\title{
A Posteriori Processing for Estimation of Low Cycle Fatigue Failure in SESMA Wires
}

\author{
V. L. Sateesh ${ }^{1}$, Senthilkumar P. ${ }^{2}$, Satisha $^{3}$, G. N. Dayananda ${ }^{4, *}$ \\ CSMST, CSIR-National Aerospace Laboratories, Bangalore, INDIA
}

\begin{abstract}
Super elastic shape memory alloys (SESMA) are promising materials for damping applications due to their inherent hysteresis associated solid-solid reversible phase transformations. These transformations induce a large recoverable strain in the material. In most of the applications, SMA is used in the form of thin wires subjected to low cycle fatigue. This paper presents the experimental investigations on low cycle fatigue behavior of the SESMA thin wires subjected to various loading conditions. An attempt is also made to estimate the low cycle fatigue life of SESMA. The dissipated energy during the transformation is used as the key parameter to estimate the life cycles. From the results it can be seen that the estimation of the life cycles are well in agreement with the experimental fatigue life of the SESMA samples.
\end{abstract}

Keywords: Low cycle fatigue, SESMA, hysteresis

\section{Nomenclature}

$A_{f}$

$A_{S}$

$M_{f}$

$M_{s}$
Austenite finish temperature

Austenite start temperature

Martensite finish temperature

Martensite start temperature

*corresponding author

Email address: dayanand@nal.res.in (G. N. Dayananda)

${ }^{1} \mathrm{Sr}$. Scientist

${ }^{2}$ Principal Scientist

${ }^{3} \mathrm{JTA}$

${ }^{4}$ Chief Scientist 


$\begin{array}{ll}E_{d} & \text { Energy dissipated during a cycle } \\ E_{r} & \text { Strain energy } \\ E_{t} & \text { Energy of test sample for } 500 \text { cycles } \\ \varepsilon & \text { Strain } \\ \varepsilon_{\text {Bmax }} & \text { Maximum strain for benchmark problem } \\ \varepsilon_{\text {Bmin }} & \text { Minimum strain for benchmark problem } \\ \varepsilon_{t \max } & \text { Maximum strain for test specimen } \\ \varepsilon_{\text {tmin }} & \text { Minimum strain for test specimen }\end{array}$

\section{Introduction}

Shape memory alloys (SMA) have attracted the attention of researchers in the recent past in view of their superior actuation and damping capabilities. These materials exhibit phase transitions due to an external stimuli in the form of temperature and/or mechanical loading. The typical shape memory behavior is shown in the Fig. 1. It is well known that, SMA material will be in the austenite phase at the high temperature and transforms to lower temperature martensite phase by either lowering the temperature (Fig. 1a, shape memory effect) or by the application of mechanical loading (Fig. 1b). The phase transformation from the high temperature austenite phase to low temperature martensite phase with the application of mechanical loading alone is referred to as stress induced transformation. During the transformation, large recoverable strains will be induced in the material. The mechanical loading induced transformation that results in large elastic strains is referred to as the super elasticity in shape memory materials (Ref. Fig. 1b). The forward transformation is exothermic in nature and the reverse transformation from martensite to austenite phase is endothermic. These transformations dissipate the mechanical energy in the form of heat. Super elastic shape memory (SESMA) alloys are best suitable for damping applications due to their inherent damping nature. In most of these applications, wires are often used under cyclic conditions at various frequencies and with large amplitudes of loading. Therefore, degradation and fatigue life are of important concerns. The low cycle fatigue study of SMA wires is quite involved as these wires go through both solid-solid phase transitions and plastic deformations simultaneously during cycles of loading. The existing literature of SMA focuses basically on two areas of research interest, namely, experimental studies on phase transformations [1]-[14] and modeling of the transformation behavior [15]-[24]. The modeling of transformation behavior 
in the SMA can be classified as the phenomenological models [15]-[20] and those based on thermodynamic formulation [21]-[24]. This paper focuses on experimental investigations on SESMA wires, hence literature pertaining to experimental investigation of SESMA wires has been discussed here.

Liu et al. [1] have shown from microstructure studies that a high density of dislocations have been generated in the martensite variants during the fatigue test of SESMA wires. McKelvey and Ritchie [2] have carried out experimental investigation on the fatigue crack propagation behavior of the NiTi SE SMA wires and it was found that crack growth rate in SE SMA wires is a function of temperature. Eggeler et al. [3] have experimentally studied the structural and functional fatigue behavior of NiTi SE SMA wires and it has been concluded that the plateau stresses and the area of the stressstrain hysteresis decreases with increase in cycle number. Further, it has been found that the irreversible strain accumulates during strain controlled tension tests. Pieczyska et al.([4] and [5]) and Tobushi et al. [6] have used infrared thermography for measuring the thermal signatures during mechanical cycling. The IR measurements were helpful in identifying the phase transformation in $\mathrm{Ni}-\mathrm{Ti}$ wires. It was found from the experiments that the temperature distributions during loading and unloading of the SESMA wire were inhomogeneous in the range of martensitic and reverse transformations. Chang et. al. [7] have modeled the cyclic behavior SMA wire under uniaxial loading using 1D continuum model. Experiments have also been carried out using infrared measurements. These measurements have been used to validate the theoretical simulated thermal fields. The dissipation property of the SESMA depends on the rate of strain and temperature. Des Roches et al. [8], Lin et. al. [9] and Dayananda and Subba Rao [10] investigated the strain rate effects and showed as the test frequency increases the loading and unloading plateau stresses increase while the damping markedly decreases. This is because transformation stress depends on the temperature of the wire. Further, the temperature of the wire increases with increase in strain rate. Choi et al. [11] studied the effect of dynamic loading on the behavior of shape memory alloy bars and concluded that the initial strain and frequency of loading did not affect the mechanical properties. Further, they inferred that there is a change in the Young's modulus of the material with respect to number of cycles and the modulus stabilizes after a couple of hundred cycles. Chen et al. [12] have studied the compressive stress-strain behavior of SESMA wires under quasi-static loading and high strain loadings. It was found that the plateau stress is strain-rate dependent. Heller et al[13] have 
developed a testing procedure for thin wires under tension, torsion bending and combined loads. It has been concluded that the SESMA has good damping capabilities in low frequency loads. The effect of strain amplitude on fatigue life of the SESMA has been evaluated for $0.5 \mathrm{~Hz}$ frequency on dog-bone specimens by Maletta et al. [14]. In addtion the fatigue life of the SESMA is modeled using the Coffin-Manson approach. It was observed from the experiments that there is a variation in fatigue life of the specimens for a constant strain amplitude.

Cyclic studies on SESMA thin wires have been carried out with different loading frequencies to study the effect of frequencies on the fatigue life of SEMSA at constant ambient temperature. Further, as shape memory alloys exhibit the high thermo-mechanical coupling owing to heat of transformations during mechanical loading and unloading, it is proposed that the pattern associated with the dissipation of the energy in the form of heat of transformation gives a-priori indication of the failure. A method has been therefore established to estimate the fatigue life of the SESMA wire based on the pattern of dissipated energy evolution during the first few cycles.

\section{Experimental Details}

To study the fatigue behavior of the NiTi superelastic shape memory alloy wires (SESMA), tension-tension cyclic tests have been carried out with various frequencies. The composition of the wire considered for this study is $54.3 \% \mathrm{Ni}$ and $45 \% \mathrm{Ti}$ by weight. The cold worked specimen is heat treated to a temperature of $500^{\circ} \mathrm{C}$ for 15 min and water quenched. The DSC report for the specimen has been shown in the Fig. 2. The transformation temperatures have been tabulated and given in Table 1 . The diameter of the wire considered for the study is $0.6 \mathrm{~mm}$ and the guage length of the wire is 30 $\mathrm{mm}$. The specimens were tested in displacement control mode by using computer controlled thermo-mechanical fatigue machine (Electroforce 3330). A thermal control chamber has also been established to maintain the ambient temperature $22^{\circ} \mathrm{C}$ with a variation of $\pm 0.5^{\circ} \mathrm{C}$. This is essential to avoid the affect of ambient temperature variation on the SESMA behavior.

The amplitude of the displacement of the wire is varied as following, initially the specimen is loaded till $6 \%$ strain level and then cycled between $1.5 \%$ to $6 \%$ strain. The applied displacement is sinusoidal in nature. Keeping

the specimen in pre-deformed condition avoids the buckling due to residual 
Table 1: Transformation temperatures of SESMA material in ${ }^{\circ} \mathrm{C}$

\begin{tabular}{cccc}
\hline$M_{f}$ & $M_{s}$ & $A_{S}$ & $A_{f}$ \\
\hline 6.8 & 12.5 & 11.9 & 17.7 \\
\hline
\end{tabular}

deformations and ensures the wire is in straight condition through out the experiment.

\section{Results and Discussion}

The effect of frequencies on cyclic and low cycle fatigue (LCF) behavior has been investigated for constant amplitude of deformations and the corresponding observations are given in the following sections. Further, the analysis has been carried out to predict the LCF life estimation and is presented.

\subsection{Cyclic testing}

Cyclic tests have been carried out with different frequencies to study the effect of frequency on the cyclic behavior of the SESMA thin wires. The typical hysteresis loop at the frequency of $0.01 \mathrm{~Hz}$ for the first two cycles is shown in Fig. 3. The input displacement signal with the variation of time is also shown in the Fig. 3. The stress-strain relation for the second cycle has been given in the Fig. 4 . To generate the stress-strain relation, the frequencies $0.01,0.05,0.1,1,10,15$ and $25 \mathrm{~Hz}$ have been considered. From the figure it can be seen that when the frequency of loading increases the area inside the hysteresis loop decreases. This observation is in line with the findings of Des Roches et al. [8], Lin et. al. [9] and Dayananda and Subba Rao [10]. This can be seen clearly from the Fig. 5 where the energy dissipated during the transformation is plotted against the frequency. The energy dissipated due to the transformation for a particular cycle can be obtained by calculating the area enclosed inside the hysteresis for that particular cycle. The procedure given in the Ref.[10] is followed to calculate the dissipated energy.

The pictorial representation of dissipated energy, and recovered elastic work are shown in Fig. 6. Here, $E_{d}$ is the energy dissipated during the transformations and $E_{r}$ is the recovered strain energy. In the figure, Ed is the area enclosed in the hysteresis loop and hatched with right inclined bars, whereas other than $E_{d}$ remaining hatched portion is $E_{r}$ (left inclined bars). 
Further, from the Fig. 4, the martensitic transformation stress $\left(\sigma_{m}\right)$ increases with the increase in frequency except for the $1 \mathrm{~Hz}$ frequency. This can be attributed to the heat transfer with the surroundings. The reverse transformation stress also increases with increase in the frequency. In addition, the austenite elastic deformation is independent of frequencies in the tested range of frequencies, while the elastic unloading and martensitic plateau of reverse transformation coupling increases with increase in frequency. It can also be seen from the Fig. 4 that as the frequency increases the hysteresis loops translate upwards and stabilizes over the frequencies of $10 \mathrm{~Hz}$.

\subsection{Low cycle fatigue study}

The effect of loading frequencies on the fatigue life of SESMA thin wires has been studied by considering various loading frequencies namely, 0.01, $0.05,0.1,1,10,15,20,25,30$ and $35 \mathrm{~Hz}$. The relation between the number of cycles to failure versus the frequency of the loading is given in the Fig. 7 . From the figure, it can be observed that, the low cycle fatigue life of the SESMA wire is more for the wires that are under going low frequency loading. The behavior of stress-strain relation for the cycles 1, 2, 100, 1000, 2000, 3000,4000 and the cycle before failure for the loading frequency of $0.01 \mathrm{~Hz}$ is showing in Fig. 8. The area of the hysteresis loop decreases with increase in the cycle number. Further, the martensitic transformation stress $\left(\sigma_{m}\right)$ decreased with increase in the cycle number. In addition, maximum and minimum stresses have also been reduced with increase in the cycles. It can also be seen from the figure that the martensitic elastic deformations take place from 100th cycle and the plateau region of martensitic transformations reduces with increase in cycle number. The area enclosed inside the hysteresis loop over the number of cycles until the failure for the frequencies $0.01,0.1,1$, $10 \mathrm{~Hz}$ is shown in the Fig.9. The dissipated energy due to the transformation is more in the initial cycles and rate of change of dissipated energy after 500 cycles is minimal.

The cumulative energy calculated over the number of cycles till the failure is plotted against the number of cycles to failure and given in Fig. 10. From the Fig. 10 it can be seen that the number of cycles to failure is high in the case of the wires that dissipate more energy. This can be attributed to the accumulation of more plastic strains for the high frequency loadings (where the energy dissipation is less) when compared with low frequency loadings. The accumulation of plastic strain reduces the transformation strains and hence the life of the specimen also reduces. Further, the relation between 
cumulative energy and number of cycles to failure shows bilinear behavior. The frequencies below $5 \mathrm{~Hz}$ shows lower rate of increment in the life cycles with the reduction in frequencies (i.e. the slope of the line between the higher frequencies with number of cycles to fail is more than that of the frequencies lower than $5 \mathrm{~Hz}$ with number of cycles to fail) than that of the higher frequencies. In the low frequency region there is enough time for the transformation (heating) to be effective and adequate time for reverse transformation (cooling) as well. However in the high frequency region inadequate time available for phase transformations to takes place and the influence of plastic strain and related effects results in the different slope.

\subsection{LCF life estimation}

The relation between number of cycles to failure and the energy dissipated through the hysteresis gives the estimation for the fatigue life of SESMA. The energy dissipated through the hysteresis can be considered as a key parameter. Further, as the energy of different frequencies shows bilinear behavior with the number of cycles, the estimations are more close to the actual values. To estimate the LCF life of SESMA, it is sufficient to consider the dissipated energy upto about 500 cycles. This is because after the 500 cycles the changes in dissipated energy as a function of cycles is minimal (Ref. Fig. 9). In other words, the hysteresis loops stabilize at about 500 cycles at the maximum for high frequency loading. The average dissipated energy for different frequencies upto 500 cycles has been plotted with the corresponding average number of cycles till the failure and the same is given in the Fig. 11. From the Fig. 11 it can be seen that the relation between number of cycles to failure with the dissipated energy upto 500 cycles shows a linear behavior.

As the area enclosed in the stress-strain graph depends on the variation of the strain amplitude, the fatigue life of the SESMA also varies with the magnitude of the strain amplitude. The variation of the deformation has to be accounted while estimating fatigue life of the SESMA. Therefore, the dissipated energy of the sample can be normalized for the tested deformations as

$$
E=E_{t} \frac{\varepsilon_{B \max }}{\varepsilon_{\text {tmax }}} \frac{\varepsilon_{B \max }-\varepsilon_{B \min }}{\varepsilon_{t \max }-\varepsilon_{t \min }}
$$

where, $E_{t}$ is the energy of the test specimen for 500 cycles, $\varepsilon_{\text {Bmax }}$ is the

maximum strain of the bench mark test, $\varepsilon_{\text {tmax }}$ is the maximum strain of the 
test specimen, $\varepsilon_{B \min }$ is the minimum strain of the benchmark test and $\varepsilon_{t \max }$ is the minimum strain of the test specimen.

The estimation of the LCF life of SESMA is validated by carrying out the experiments on the thin SESMA wire subjected to two load cases. In the first case, strain amplitude is varied from $3 \%$ to $6 \%$ with five different frequencies viz, 1, 5, 12, 25 and $30 \mathrm{~Hz}$. The second case consists of the strain amplitudes that is varied from $2 \%$ to $5 \%$ with the frequencies of $1,5,25$ and $30 \mathrm{~Hz}$. The estimation of the life cycles and the actual low cycle fatigue life of the samples from the experiments with various frequencies are given in Table 2 for the case I and in Table 3 for case II. The estimated low cycle fatigue life of the SESMA is calculated as follows. For illustrating the procedure for estimation, the experiment with strain amplitude of $3 \%$ to $6 \%$ is considered along with $1 \mathrm{~Hz}$ frequency. The dissipated energy for the first 500 cycles for $1 \mathrm{~Hz}$ sample is $1564.8 \mathrm{MJ} / \mathrm{m}^{3}$. The dissipated energy factorized from Eq. 1 is found to be $2347 \mathrm{MJ} / \mathrm{m}^{3}$. The number of cycles from Fig. 11 is 2525, whereas this sample has failed at 3741 cycles. The error in the estimation is about $32.5 \%$.

Table 2: Estimated number of cycles to failure for SESMA subjected to different frequencies with amplitude of displacement varied from $3 \%$ to $6 \%$

\begin{tabular}{c|c|c|c|c|c}
\hline Frequency & $E_{d}$ & $\begin{array}{c}\text { Fac. } E_{d} \\
(\text { Eq. 1) }\end{array}$ & $\begin{array}{c}\text { No. of Cycles } \\
\text { from (Fig. 11) }\end{array}$ & $\begin{array}{c}\text { No. of cycles } \\
\text { to fail }\end{array}$ & \% error \\
\hline $\mathrm{Hz}$ & $M J / m^{3}$ & $M J / m^{3}$ & & & \\
\hline 1 & 1564.8 & 2347.2 & 2525 & 3741 & 32.5 \\
1 & 1399.5 & 2099.1 & 2233 & 2775 & 19.7 \\
5 & 1201.6 & 1802.4 & 1883 & 2407 & 21.7 \\
5 & 1172.9 & 1759.4 & 1833 & 2392 & 23.3 \\
12 & 1080.8 & 1624.2 & 1670 & 1916 & 12.3 \\
25 & 1049.7 & 1574.5 & 1615 & 1626 & 0.67 \\
25 & 1064.2 & 1596.3 & 1640 & 1840 & 10.8 \\
30 & 839.6 & 1259.4 & 1244 & 1322 & 5.9 \\
\hline
\end{tabular}

From the Tables. 2 and 3 it can be seen that the maximum error in estimation of low cycle fatigue life is about $32.5 \%$. This error in estimation is well within the deviation of the experimental fatigue life of the sample for that particular frequency. The deviation in the experimental values of life cycles for $1 \mathrm{~Hz}$ frequency is 1709 and the variation is about $71 \%$. 
Table 3: Estimated number of cycles to failure for SESMA subjected to different frequencies with amplitude of displacement varied from $2 \%$ to $5 \%$

\begin{tabular}{c|c|c|c|c|c}
\hline Frequency & $E_{d}$ & $\begin{array}{c}\text { Fac. } E_{d} \\
(\text { Eq. 1) }\end{array}$ & $\begin{array}{c}\text { No. of Cycles } \\
\text { from (Fig. 11) }\end{array}$ & $\begin{array}{c}\text { No. of cycles } \\
\text { to fail }\end{array}$ & \% error \\
\hline $\mathrm{Hz}$ & $M J / m^{3}$ & $M J / m^{3}$ & & & \\
\hline 1 & 1687.4 & 3037.4 & 3338 & 3150 & 5.9 \\
5 & 1375.6 & 2476.2 & 2677 & 2617 & 2.3 \\
25 & 1122.7 & 2020.8 & 2141 & 1663 & 28.7 \\
30 & 1019.5 & 1835.1 & 1922 & 2112 & 9.0 \\
\hline
\end{tabular}

\section{Conclusions}

Experimental investigations of low cycle fatigue life of the superelastic shape memory alloys have been carried out. The effect of the frequency on the fatigue life of the SESMA has been studied. From the results it can be observed that the fatigue life of the SESMA decreases with increase in the testing frequency. The dissipated energy due to hysteresis effect is calculated for different frequencies and relation with number of cycles to failure is established. The dissipated energy due to the phase transformation decreases with increase in cycle number. Further, as the frequency increases, the dissipated energy will decrease. In addition the dissipated energy shows bilinear behavior with the number of cycles to failure in the tested range of frequencies.

Fatigue life of the SESMA sample is estimated by using energy dissipated for first 500 cycles. For this, the data corresponding to the dissipated energy for 500 cycles and the corresponding experimental fatigue life of test specimens with various frequencies has been used. The maximum deviation in the estimated fatigue life is $32 \%$ compared to experimental values. 


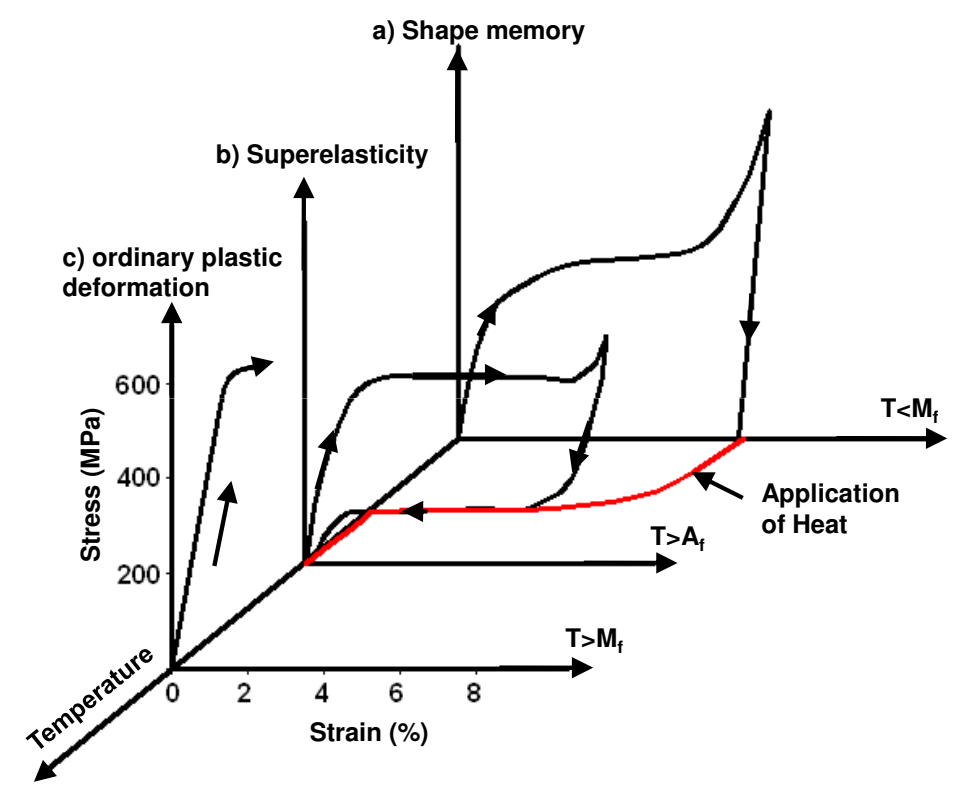

Figure 1: Shape memory behavior

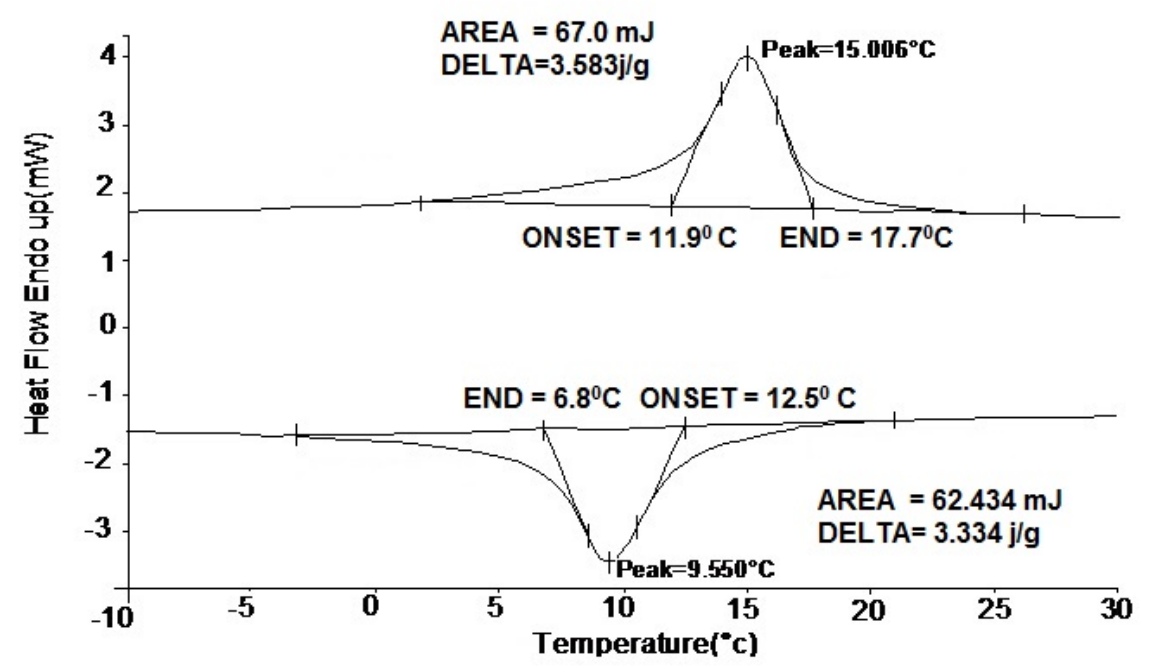

Figure 2: DSC results for $0.6 \mathrm{~mm}$ test sample 

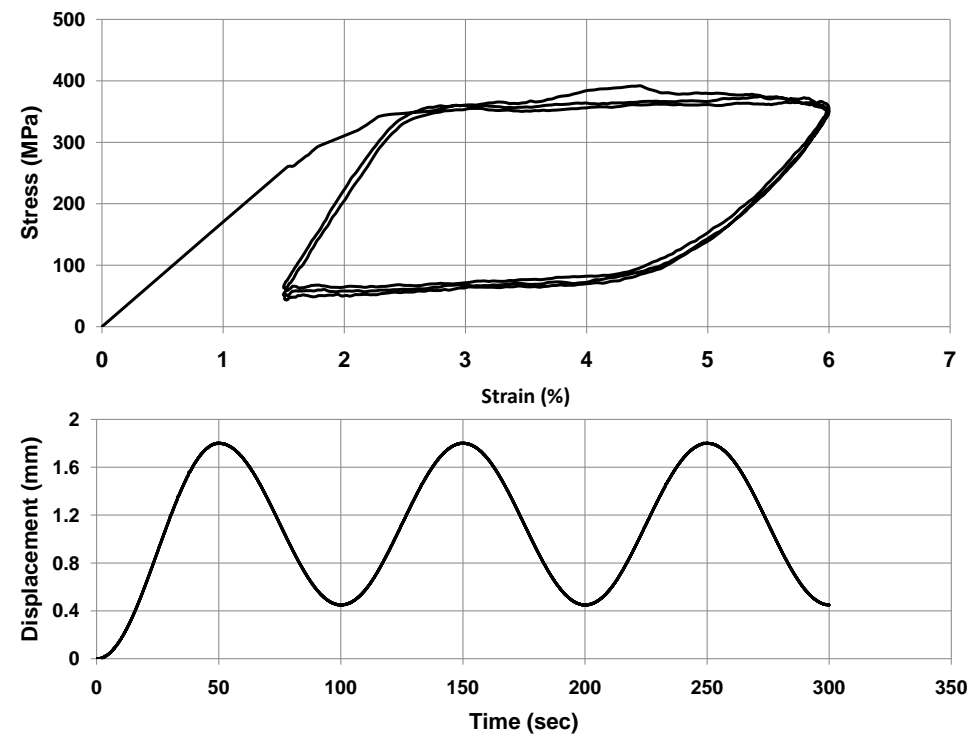

Figure 3: Stress strain behavior of SESMA wire subjected to $0.01 \mathrm{~Hz}$ frequency

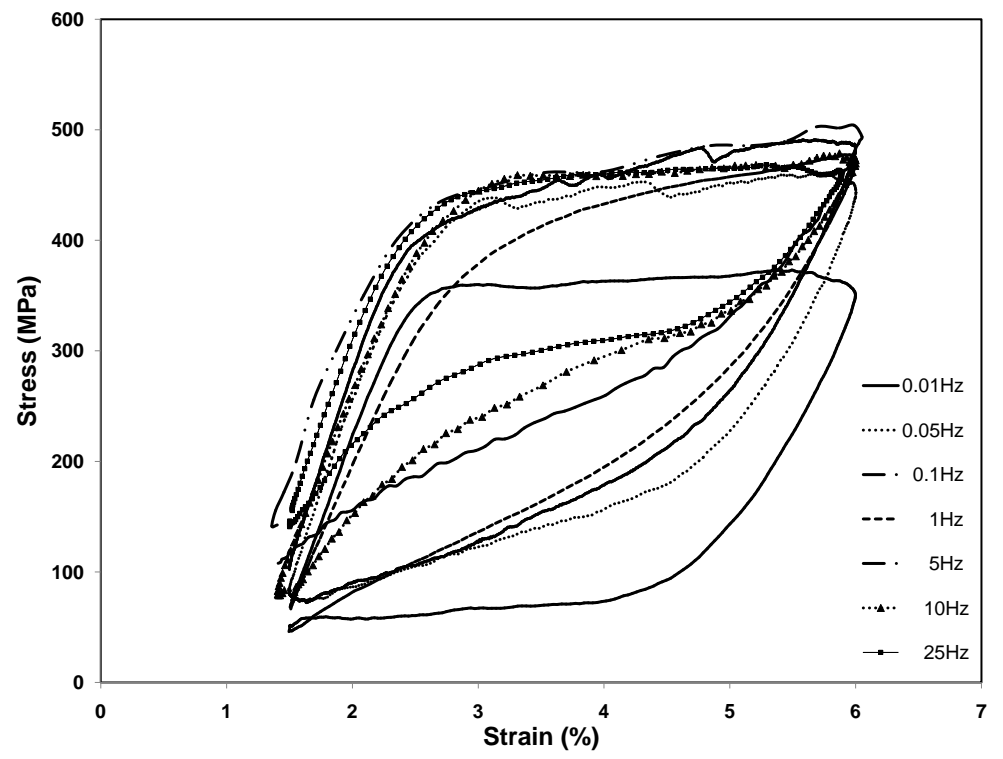

Figure 4: Stress strain behavior of SESMA wire for second cycle subjected to various frequencies 


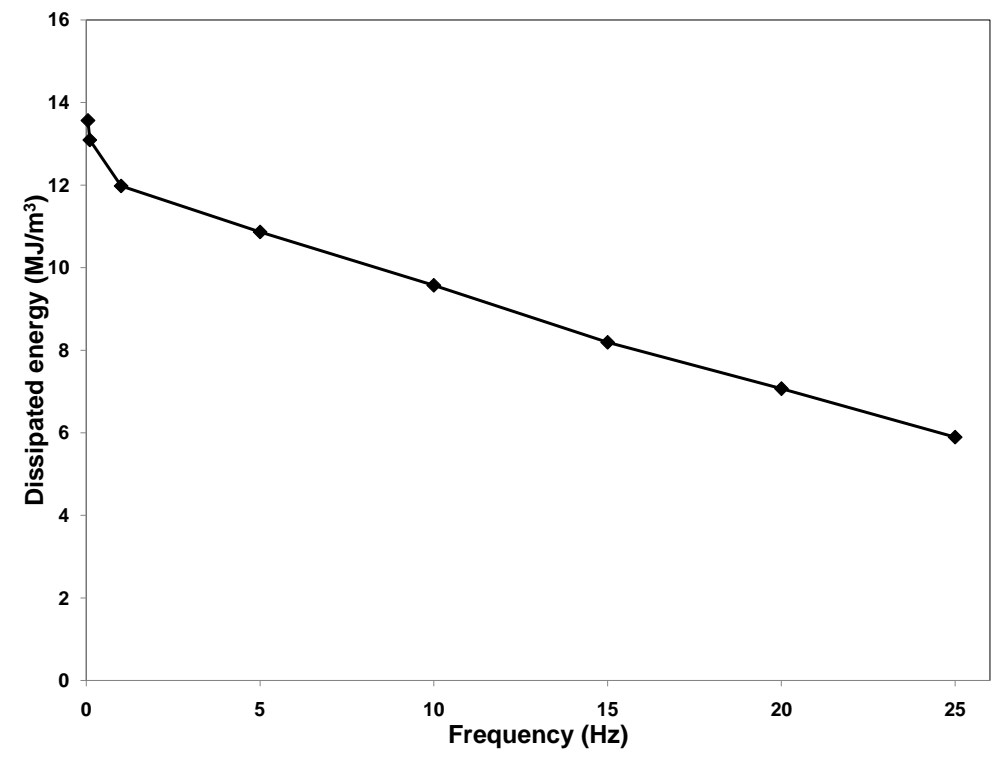

Figure 5: Dissipated energy during second cycle for various frequencies

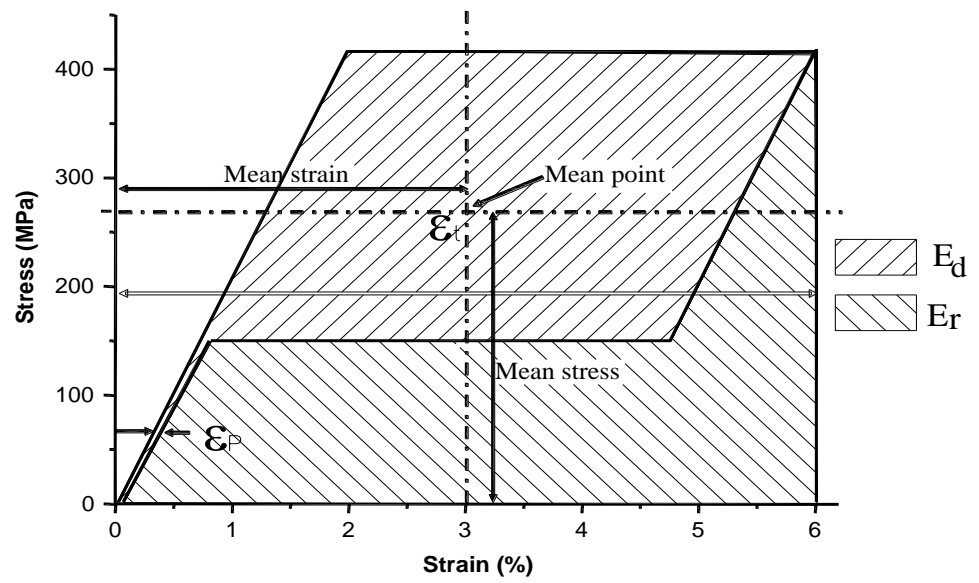

Figure 6: Pictorial representation of dissipated energy $E_{d}$ and recoverable energy $E_{r}$ 


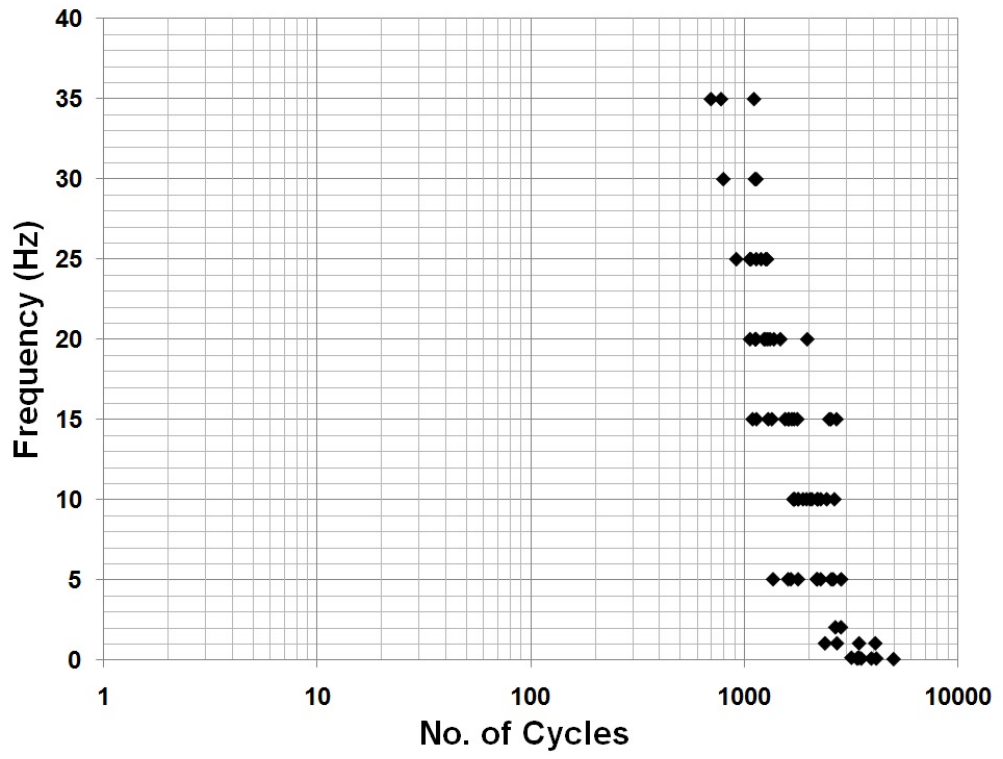

Figure 7: Number of cycles versus frequency

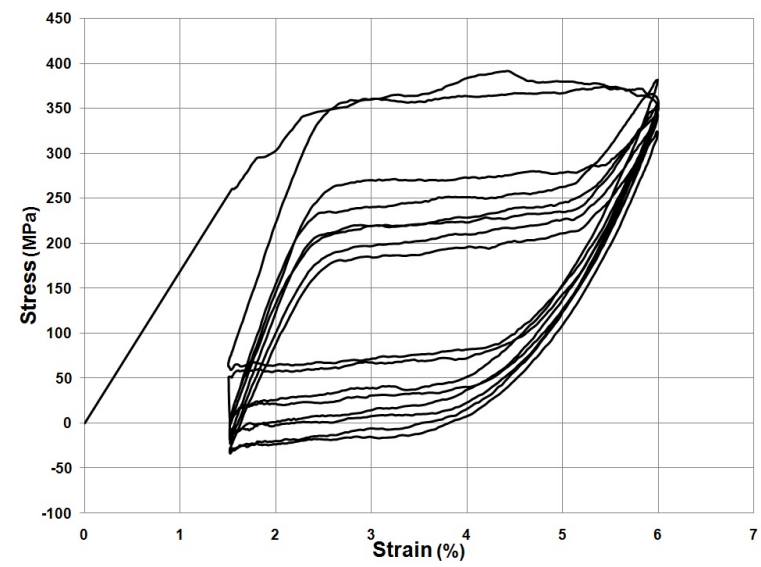

Figure 8: Stress strain behavior of SESMA wire for different cycles to failure subjected $0.01 \mathrm{~Hz}$ frequency 


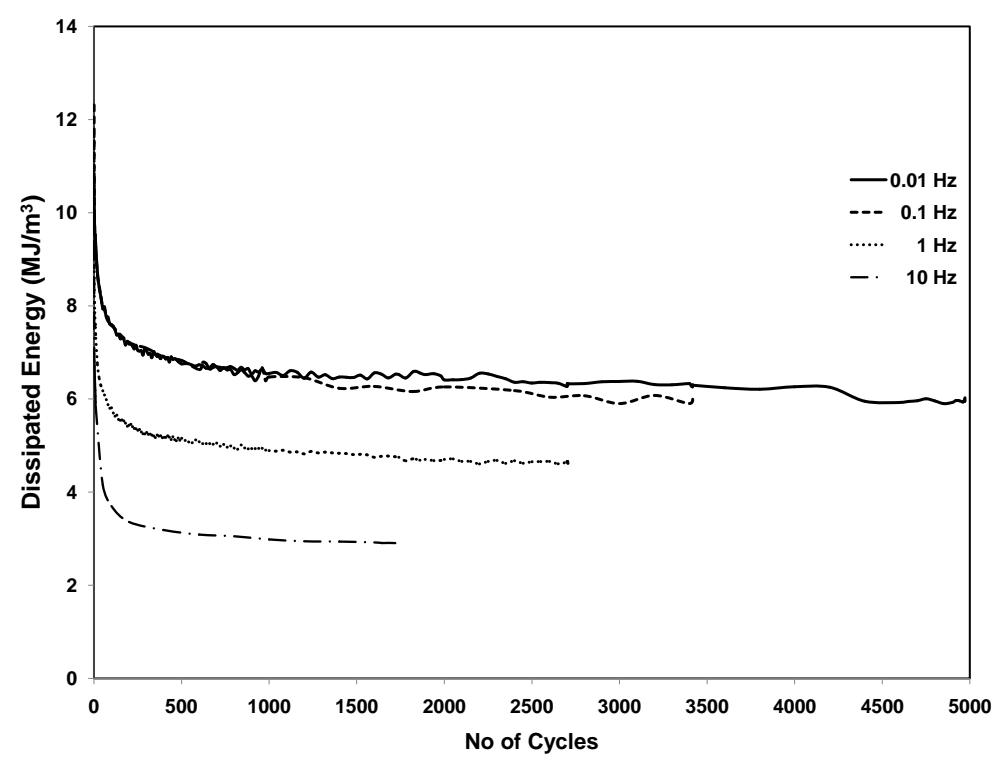

Figure 9: Dissipated energy over the number of cycles for different frequencies

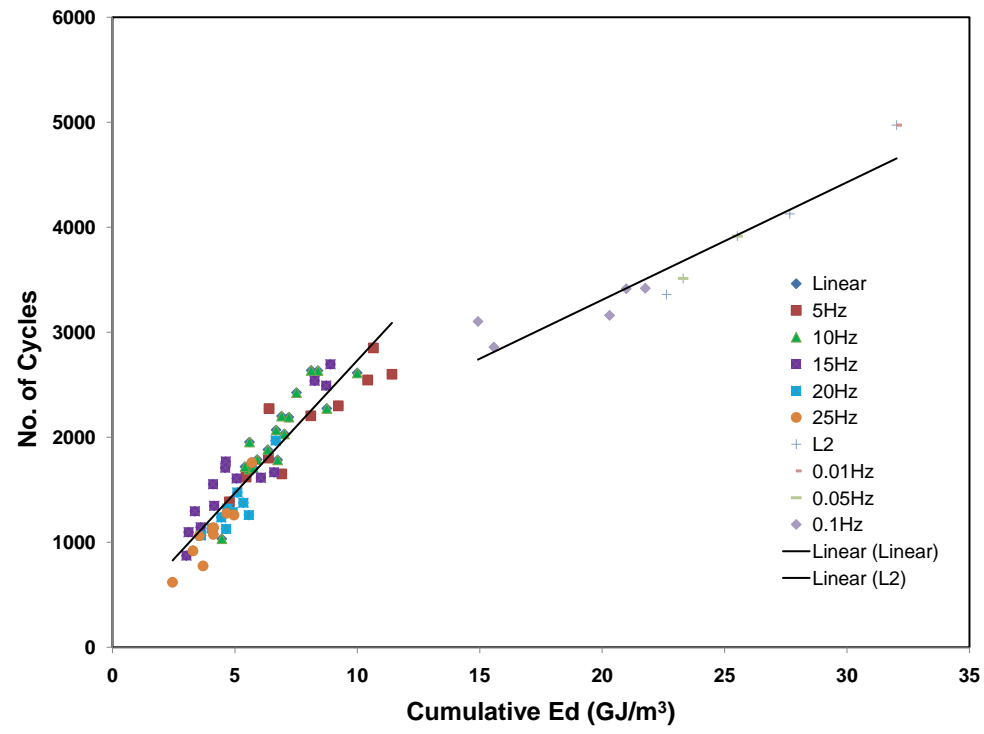

Figure 10: Variation of cumulative dissipated energy with number of cycles 


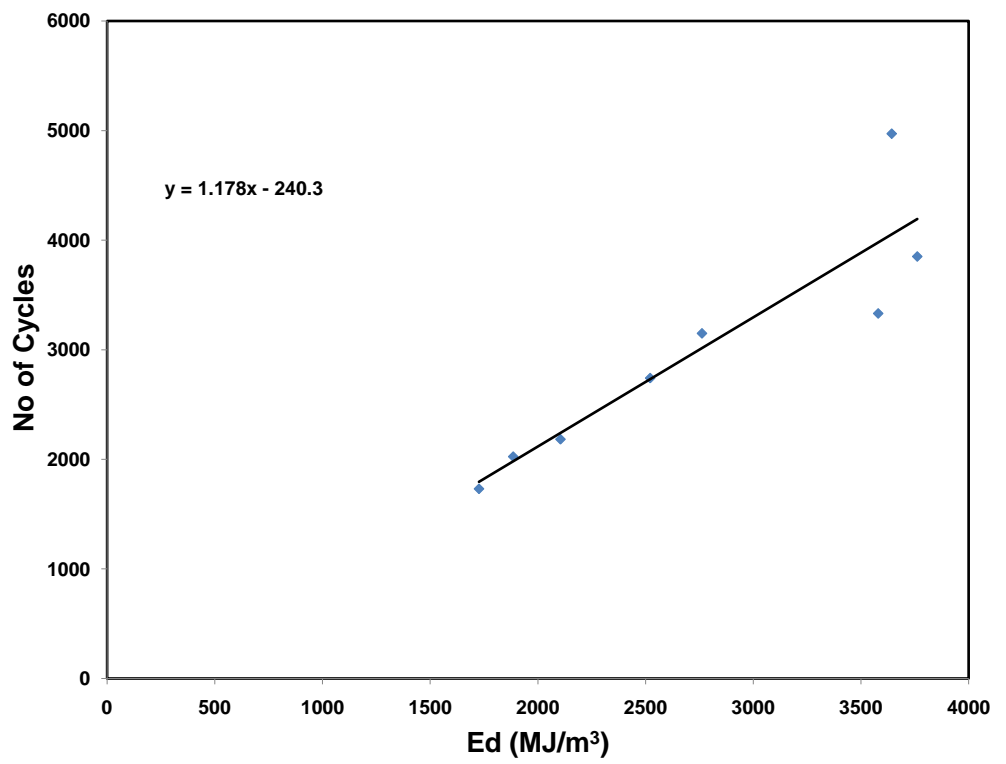

Figure 11: Relation of Cumulative average energy of 500 cycles subjected to various frequencies with number of cycles to failure 


\section{References}

[1] Young Liu, Zeliang Xie and Jan Van Humbeeck, "Cyclic deformation of NiTi shape memory alloys," Materials Science and Engineering A, Vol. 273-275, 1999, pp. 673-678.

[2] Mckelvey A. L. and Ritchie, R. O., "Fatigue - crack growth behavior in the superelastic and shape memory alloy NiTinol," Metallurgical and Material Transactions A, Vol. 32, 2001, pp. 731-743.

[3] Eggeler G., Hornbogen E., Yawny A., Heckmann A. and Wagner M., "Structural and functional fatigue of NiTi shape memory alloys," $M a-$ terials Science and Engineering A, Vol. 378, 2004, pp. 24-33.

[4] Pieczyska E.A., Gadaj S.P., Nowack W.K. and Tobushi H., "Thermomechanical investigation of martensitic and reverse transformations in TiNi shape memory alloy," Bulletin of the Polish academy of sciences - Technical sciences, Vol. 52, No. 3, 2004 pp. 165-171.

[5] Pieczyska E. A., "Activity of stress-induced martensite transformation in TiNi shape memory alloy studied by infrared technique," Journal of Modern Optics, Vol. 57, No. 18, 2010, pp. 1700-1707.

[6] Tobushi H., Piezyska E. A., Ejiri Y. and Sakuragi T., "Thermomechanical properties of shape-memory alloy and polymer and their composite," Mechanics of advanced materials and structures, Vol. 16, 2009, pp. $236-247$

[7] Chang B-C, Shaw J. A. and Iadicola M. A., "Thermodynamics of shape memory alloy wire: modelling, experiments and application," Continuum Mechanics Thermodynamics, Vol. 18, 2006, pp. 83-118.

[8] DesRoches R., McCormick J. and Delemont M., "Cyclic properties of superelastic shape memory alloy wires and bars," Journal of Structural Engineering, Vol. 130, No. 1, 2004, pp. 38-46.

[9] Lin P.H. and Tobushi H., "Influence of strain rate on deformation properties of NiTi shape memory alloy," JSME International Journal A, Vol. 39, No. 1, 1996, pp. 117-123. 
[10] Dayananda G. N., and Subbarao M., "Effect of strain rate on properties of superelastic NiTi thin wires," Materials Science and Engineering A, Vol. 486, 2008, pp. 96-103.

[11] Choi E, Nam TH, Chung YS, "Variation of mechanical properties of shape memory alloy bars in tension under cyclic loading," Material science and Engineering A, Vol. 527, 2010, pp. 4412-4417.

[12] Chen W. W., Wu Q.P., Kang J. H., and Winfree N. A., "Compressive superelastic behavior of a NiTi shape memory alloy at strain rates of 0.001-750 s ${ }^{-1}$, International Journal of Solids and Structures, Vol. 38, 2001, pp. 8989-8998.

[13] Heller L., Kujawa A., Sittner P., Landa M., Sedlák P. and Pilch J., "Quasistatic and dynamic functional properties of thin superelastic NiTi wires," The European Physical Journal Special Topics, Vol. 158, 2008, pp. 7-14.

[14] Maletta C., Sgambitterra E., Furgiuele F., Casati R., and Tuissi A., "Fatigue of pseudoelastic NiTi within the stress-induced transformation regime: a modified Coffin-Manson approach," Smart materials and structures, Vol. 21, 2012, pp. 1-7.

[15] Bekker A. and Brinson L., "Phase diagram based description of the hysteresis behavior of shape memory alloys," Acta Materialia, Vol. 46, 1998, pp. 3649-3665.

[16] Brinson L. C., "One dimensional constitutive behavior of shape memory alloys: Thermo mechanical derivation with non-constant material functions and martensite internal variable," Journal of Intelligent Materials Systems and Structures, Vol. 4, 1993, pp. 229-242.

[17] Lexcellent C., Leclercq S., Gabry B. and Bourbon G., "Two way shape memory effect of shape memory alloys: an experimental study and a phenomenological model," International Journal of Plasticity, Vol. 16, 2000, pp. 1155-1168.

[18] Auricchio F., and Sacco E., "Thermo-mechanical modelling of a superelastic shape-memory wire under cyclic stretching-bending loadings," International Journal of Solids and Structures, Vol. 38, 2001, pp. 61236145 . 
[19] Ashwin Rao, Srinivasa A.R., "A two species thermodynamic Preisach model for the torsional response of shape memory alloy wires and springs under superelastic conditions," International Journal of Solids and Structures, Vol. 50, 2013, pp.887-898.

[20] Zhu S., and Zhang Y., "A thermomechanical constitutive model for superelastic SMA wire with strain-rate dependence," Smart materials and structures, Vol. 16, 2007, pp. 1696-1707.

[21] Lubliner J. and Auricchio F., "Generalized plasticity and shape memory alloys," International Journal of Solids and Structures, Vol. 33, 1996, pp. 991-1003.

[22] Boyd J. and Lagoudas D., "A thermodynamical constitutive model for shape memory materials. Part I The monolithic shape memory alloys," International Journal of Plasticity, Vol. 12, 1996, pp. 805-842.

[23] Lagoudas D. C., Bo Z. and Qidwai M. A., "A unified thermodynamic constitutive model for SMA and finite element analysis of active metal matrix composites," Mechanics of Composite Materials and Structures, Vol. 3, 1996, pp. 153-163.

[24] Nallathambi A.K., Doraiswamy S., Chandrasekar A.S. and Srinivasan S.M., "A 3-species model for shape memory alloys," International Journal of structural changes in solids, Vol. 1, 2009, pp.149-170. 